\title{
The use of stem cells in research and therapies: Ethical, legal and social issues
}

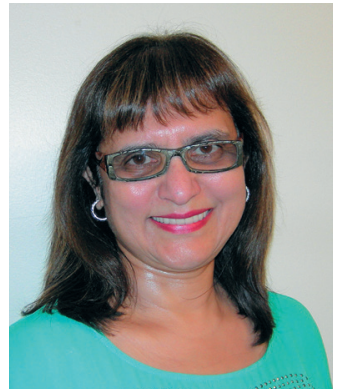

Ames Dhai

Editor

(amaboo.dhai@wits.ac.za)

Ethical, legal and social issues associated with health research in general are multiple and complex. The complexity increases when research involves human tissues, and in particular stem cells as the trajectory of the latter will include scientific and technological advances not previously explored.

In April 2013 the South African Medical Research Council published a request for applications (RFA) for a new funding opportunity called the University Flagship Awards. These Awards are the largest medical research grants awarded by the MRC. After an initial internal selection process in the country's universities and science councils, a rigorous external review process of the selected applications was undertaken. One of the successful applicants was Prof. Michael Pepper (guest editor of this issue), at the University of Pretoria. Utilising a multidisciplinary approach, from pure scientific to clinical, ethicoregulatory and social aspects, his proposal was centred on stem cells. Accomplished scientists from diverse disciplines both in South Africa and abroad are involved in this project, which aims to contribute to the alleviation of the heavy burden of disease in South Africa through the translation of high-quality, high-impact research findings into practice and policy.

This issue is specific to the ethical, legal and social issues that arise in the context of stem cell research and therapies. Articles span not only the South African setting, but also the wider global situation. First authors of all the papers published in this issue, except for 'Informed consent in clinical trials using stem cells: Suggestions and points of attention from informed consent training workshops in Japan', are investigators in the Flagship Award. The issue, and most of the research published in this supplement, is the result of funding provided by the Medical Research Council of South Africa in terms of the MRC's Flagships Awards Project SAMRC-RFA-UFSP-01-2013/ STEM CELLS.

\section{SAJBL: Flagship special stem cell edition}

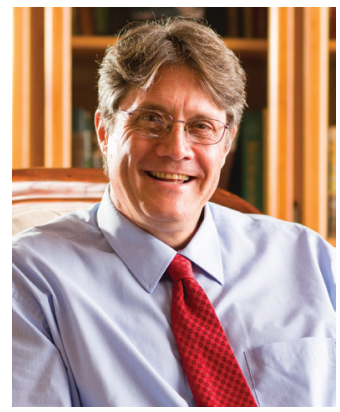

\section{Michael S Pepper}

Guest Editor

From the perspective of medical and scientific research, South Africa is well placed through its many resources to make an important positive contribution to the global knowledge base and also to the improvement of the quality of life of its patients. Our focus is on stem cells and the potential impact their clinical translation will have on the lives of many South Africans.

The ethical, legal, and social issues (ELSI) related to stem cells are numerous and complex. Critical to the success of research and therapy in the stem cell field is a well-balanced legislative environment. Stem cell legislation in South Africa is governed principally by the National Health Act (No. 61 of 2003) and the Medicines and Related Substances Act (No. 101 of 1965). While this legislation and the associated regulations (promulgated in April 2012) provide for some of the requirements including ministerial authorisation, authorised institutions, patient informed consent, clinical trials, registration of new medicines (or biological medicines), anonymity, traceability, etc., there are a significant number of important areas in the field that are not adequately covered, and South Africa, like many other parts of the world, is being subjected to the problem of stem cell tourism.

In 2014 the South African Medical Research Council (SAMRC) awarded a University Flagship Award to the stem cell group based at the University of Pretoria (UP). The project involves scientists from diverse disciplines both in South Africa and abroad. The Flagship project entitled 'Stem cell research and therapy - addressing South Africa's disease burden' aims to contribute to the alleviation of the heavy burden of disease in South Africa through the translation of high-quality, high-impact research findings into practice and policy. Some of the objectives from an ELSI perspective are:

- To critically evaluate existing legislation in South Africa dealing with human tissues and in particular stem cells.

- To compare stem cell legislation in South Africa to legislation in the European Union and the USA, and also in other developing nations.

- To propose legislation in areas where important gaps currently exist such as the use of autologous stem cells and the requirements relating to cells that have been manipulated ex vivo (including the notion of 'minimally-manipulated').

- To determine the presence and magnitude of stem cell tourism in South Africa and to assist the National Department of Health in establishing measures to halt this practice.

In order to achieve these objectives, and in collaboration with the South African Journal for Bioethics and Law, a call was issued in late 
2014 for proposals for articles for a special issue on stem cells. The ten manuscripts published herein were chosen after a rigorous selection process, and represent, we believe, a relevant and balanced overview of many of the important stem cell issues facing patients, medical and legal practitioners, researchers and business.

The special edition has been divided into five sub-sections each with two articles. The first deals with human tissue and stem cell legislation both in South Africa and abroad. The second deals with pluripotent stem cells, which include embryonic and induced pluripotent stem cells. The third section deals with stem cell tourism and the fourth with informed consent. The fifth and final section deals with biobanks and also takes an in-depth look at the notion of benefit sharing.
In order to achieve the objective of reducing the heavy burden of disease currently being experienced in South Africa, particularly in the context of new and innovative therapies, it is critical that the legislative environment is robust to ensure patient safety and to prevent exploitation of emotionally vulnerable individuals. However, it is also necessary to ensure that the legislation is not restrictive with regard to investment into new technologies and the emergence of start-up biotechnology and other companies. We believe that by being directly involved in the stem cell field and with a keen interest in the legislation, we are well placed to assist the government and other entities to ensure the realisation of these objectives in a well-balanced legislative environment. The publication of this special edition will, we believe, make an important contribution towards achieving these objectives. 